\title{
"MitoTea": Geranium robertianum L. decoctions decrease blood glucose levels and improve liver mitochondrial oxidative phosphorylation in diabetic Goto-Kakizaki rats ${ }^{\star}$
}

\author{
Fernanda M. Ferreira ${ }^{\circledR}$, Francisco Peixoto², Elsa Nunes3 ${ }^{3}$, Cristina Sena ${ }^{3}$, Raquel Seiça ${ }^{3}$ and \\ Maria Sancha Santos ${ }^{4}$ \\ 1 Department of Environment (CERNAS), Agricultural College of Coimbra - Polytechnic Institute of Coimbra, Bencanta, Coimbra, Portugal; \\ ${ }^{2}$ Chemistry Department (CECAV), University of Trás-os-Montes \& Alto Douro, Vila Real, Portugal; ${ }^{3}$ Department of Physiology and Institute of \\ Biomedical Research in Light and Image, Faculty of Medicine, University of Coimbra, Portugal; ${ }^{4}$ Department of Life Sciences, Center for Neuro- \\ sciences and Cell Biology of Coimbra, University of Coimbra, Portugal
}

\begin{abstract}
Several chemical compounds found in plant products have proven to possess beneficial properties, being currently pointed out due to their pharmacological potential in type 2 diabetes mellitus complications. In this context, we studied the effect of Geranium robertianum L. (herb Robert) leaf decoctions in Goto-Kakizaki (GK) rats, a model of type 2 diabetes. Our results showed that oral administration of $G$. robertianum leaf decoctions over a period of four weeks lowered the plasma glucose levels in diabetic rats. Furthermore, the treatment with G. robertianum extracts improved liver mitochondrial respiratory parameters (state 3 , state 4 and FCCP-stimulated respiration) and increased oxidative phosphorylation efficiency.
\end{abstract}

Keywords: Goto-Kakizaki (GK) rats, type 2 diabetes mellitus, Geranium robertianum L., Vaccinium myrtillus L., herbal medicine, oxidative phosphorylation

Received: 25 August, 2010; revised: 08 October, 2010; accepted: 22 October, 2010; available on-line: 01 November, 2010

\section{INTRODUCTION}

In the last decades, globalization has lead to Western lifestyle generalization and to the subsequent increasing rate of childhood and adult obesity, metabolic syndrome and type 2 diabetes mellitus that have attained pandemic dimensions (WHO, 2006).

Diabetes mellitus is a complex and multifarious group of disorders that disturb the metabolism of carbohydrates, fat and protein, with one common manifestation - hyperglycaemia (WHO, 1980). Hyperglycaemia causes severe complications associated with diabetes, such as nephropathy, retinopathy, neuropathy and cardiovascular diseases, which severely impair the diabetic patients' life quality (Engelgau \& Geiss, 2000; Reusch, 2003; Yorek, 2003). Hence, the major purpose of diabetes therapy is to attain normal glycaemic levels (Agius, 2007; Yu et al., 2010). Nevertheless, due to the complex nature of the disease, it usually remains unreachable by using regular therapies, including chemical anti-hyperglycaemiant agents.

Medicinal plants, used in the folk medicine since ancient times, are being rediscovered for diabetes therapy and seem to be an important and useful alternative (or complementation) to the synthetic drugs used in type 2 diabetes' therapy. Despite the increasing use of medicinal plants in diabetes mellitus treatment (Ryan et al., 2001), there is little knowledge about the mechanism of action and the therapeutic effects of several medicinal plants with anti-diabetic action attributed by folk medicine (Jayakumar, 2010).

Infusions and decoctions prepared from leaves of Geranium robertianum L., known as herb Robert or red Robin, are described as anti-hyperglycaemiant and commonly used in Portuguese herbal medicine (Castro, 1998; Cunha et al., 2009). In vivo studies performed with this plant extracts are sparse.

To evaluate the anti-hyperglycaemiant effect of this plant, we used the Goto-Kakizaki (GK) rat, a non-obese spontaneous animal model of type 2 diabetes mellitus (Goto \& Kakizaki, 1981). Several studies indicate that GK rat is a good model to study the events at the onset of the disease (Ferreira et al., 1999c; Portha et al., 2009). Therefore, young GK rats presenting moderate hyperglycaemia were selected and used in this study, to evaluate the anti-hyperglycaemic effects of $G$. robertianum decocts.

Additionally, the effects of these water extracts on mitochondrial efficiency were also assessed, since mitochondrial impairment is a common feature of several metabolic alterations, including diabetes mellitus (Lagouge et al., 2006).

The major purposes of the present research were to evaluate the effects of $G$. robertianum decocts in blood glucose levels as well as their influence on mitochondrial activity.

\section{MATERIALS AND METHODS}

Materials. All reagents and chemicals used were of the highest grade of purity commercially available. Inhibitors and drugs were dissolved in water or ethanol. In control experiments, solvents were added to isolated mitochondria at concentrations not exceeding $0.2 \%$.

Plant material. G. robertianum was collected in Santarém region (Portugal), dried in the dark and obtained directly from "11 anos - Segredo da plan-

\footnotetext{
e-mail: fmlferreira@gmail.com

* This work was presented in the poster form at the 16th European Bioenergetics Conference (Warsaw, 2010); abstract in Biochim Biophys Acta, 1797 (Suppl): 79-80 (2010).

Abbreviations: FCCP, carbonyl cyanide $p$-trifluoromethoxyphenylhydrazone; GK, Goto-Kakizaki; OXPHOS, oxidative phosphorylation; RCR, respiratory control ratio
} 
ta - Produtos naturais e biológicos, Lda" (Seixal, Portugal). A voucher G. robertianum (No. 12751), after its botanical identification, has been deposited at the Herbarium of the University of Trás-os-Montes and Alto Douro (Vila Real, Portugal).

Preparation of extracts. Plant leaves were washed in deionised water, dried and ground to a powder. The decoction was prepared by boiling $125 \mathrm{~g}$ of the dried material in $1000 \mathrm{ml}$ of deionised water for $15 \mathrm{~min}$, filtered and centrifuged at $7000 \times g$ for $5 \mathrm{~min}$ and kept at $-20^{\circ} \mathrm{C}$.

Animals. Male spontaneously diabetic GK rats were obtained from a local breeding colony (Animal Research Center Laboratory, University Hospitals, Coimbra), established in 1995 with breeding couples from the colony at the Tohoku University School of Medicine (Sendai, Japan; courtesy of Dr. K. Suzuki). Animals were kept under controlled light and humidity conditions and with free access to powdered rodent chow (diet C.R.F. 20, Charles Rivers, France) and water (or plant decoct) in accordance with European Community guidelines. GK rats were randomly divided and housed in two separated groups, one of them drinking ad libitum the G. robertianum decoct and the other, used as a control, drinking distilled water. The experiments lasted for 4 weeks and were carried out in accordance with the National Requirements for Vertebrate Animal Research and the European Convention for the Protection of Animals used for Experimental and Other Scientific Purposes.

Glycaemia. Glycaemia in a non-fasting condition (occasional) was determined twice a week. Blood glucose levels were determined through the glucose oxidase reaction by using a glucometer (Glucometer Elite - Bayer $\mathrm{SA}$, Portugal) and compatible reactive test strips. Blood samples were collected from the tail vein.

Intraperitoneal glucose tolerance test. Intraperitoneal glucose tolerance test (IPGTT - $1.8 \mathrm{~g}$ glucose $/ \mathrm{kg}$ body mass, i.p.) was carried out after fasting glycaemia determination (fasting period 16-18 h). The concentration of blood glucose was measured 30, 60, 90 and 120 min after glucose load by the method described above.

Preparation of mitochondria. GK rats were maintained ad libitum for at least $12 \mathrm{~h}$, before being sacrificed by cervical displacement, according to a pre-established method (Gazotti et al., 1979), with slight modifications (Ferreira et al., 1997). Protein was determined by the biuret method, using BSA (bovine serum albumin) as a standard (Gornall et al., 1949).

Mitochondrial respiration. Oxygen consumption of isolated mitochondria was determined polarographically at $25^{\circ} \mathrm{C}$ with a Clark oxygen electrode connected to a suitable recorder in a closed chamber with magnetic stirring (Estabrook, 1967). Mitochondria equivalent to $1.0 \mathrm{mg}$ protein, $2 \mu \mathrm{M}$ rotenone and succinate $(5 \mathrm{mM})$, as respiratory substrate, were added to $1 \mathrm{ml}$ of reaction medium (130 mM sucrose, $50 \mathrm{mM} \mathrm{KCl,} 5 \mathrm{mM} \mathrm{MgCl}_{2}$, $5 \mathrm{mM} \mathrm{KH} \mathrm{PO}_{4}, 5 \mathrm{mM}$ Hepes, $\mathrm{pH}$ 7.2). To induce state 3 respiration, $300 \mathrm{nmol}$ of ADP (magnesium salt) was added. The respiratory control ratio (RCR) was calculated according to Chance and Williams (1956). FCCPuncoupled respiration was performed by adding $1.5 \mu \mathrm{M}$ FCCP (carbonyl cyanide $p$-trifluoromethoxyphenylhydrazone) to mitochondria energized with succinate (Ferreira et al., 1999b), after a phosphorylative cycle. In order to validate respiratory activity assays, $1 \mathrm{mM} \mathrm{KCN}$ was added and the slope due to $\mathrm{O}_{2}$ diffusion was subtracted from all traces.

Statistics. The results are presented as mean \pm SEM (standard error of mean) of the number of experiments



Figure 1. Effect of G. robertianum leaf decoction on GK rat occasional glycaemia.

Data are presented as means \pm SEM for four rats in each group. Values statistically different from control (distilled water): ${ }^{* *} P<0.01 ;{ }^{* * *} P<0.001$.

shown in table and figure legends. Statistical significance was determined using paired Student's t-test. $P<0.05$ was considered significant.

\section{RESULTS}

Our results showed that G. robertianum leaf decocts led to a significant decrease of occasional glycaemia by $35 \%$ in diabetic Goto-Kakizaki rats when compared to a control group drinking distilled water during the same period of time (four weeks) (Fig. 1). These results corroborate the popular anti-diabetic properties attributed to this plant extract. The amount of liquid ingested was significantly lower, probably related to the lower glycaemia (Table 1) and the quantity of ingested food was also decreased, as compared with the control GK group. However, no significant mass changes were observed between the $G$. robertianum and control groups during the four weeks of the experiment.

Nevertheless, intraperitoneal glucose load performed before and after the treatment with the plant decocts did not show significant differences between the two groups (Table 2).

Further, our results showed that liver mitochondria isolated from GK rats treated for four weeks with leaf

Table 1. Food and liquid intake, and mass gain of GK rats

\begin{tabular}{lll}
\hline & \multicolumn{2}{c}{ Plant extract } \\
\cline { 2 - 3 } Condition & Control & Geranium robertianum \\
\hline $\begin{array}{l}\text { Food ingested } \\
\text { (g/day per rat) }\end{array}$ & $23.7 \pm 0.4$ & $19.1 \pm 0.5^{*}$ \\
$\begin{array}{l}\text { Liquid ingested } \\
\text { (ml/day per rat) }\end{array}$ & $57.0 \pm 1.8$ & $29.0 \pm 0.8^{* *}$ \\
$\begin{array}{l}\text { Final mass } \\
(\%)\end{array}$ & $106.2 \pm 0.4$ & $105.4 \pm 1.2$ \\
\hline
\end{tabular}

The amount of food and liquid ingested was recorded 3 times a week. The final mass of each rat was expressed as the percentage of its initial mass, to limit inaccuracies. Data are presented as means \pm SEM for four rats in each group. Values statistically different from control (distilled water): ${ }^{*} P<0.05 ;{ }^{* *} P<0.01$. 
Table 2. Glycaemia in fasting condition and after glucose loading

\begin{tabular}{|c|c|c|c|}
\hline & & \multicolumn{2}{|c|}{ Glycaemia (mM) } \\
\hline & & Control & G. robertianum \\
\hline \multirow{5}{*}{ } & fasting & $6.0 \pm 0.3$ & $5.4 \pm 0.0$ \\
\hline & $30 \mathrm{~min}$ & $22.6 \pm 2.3$ & $22.5 \pm 0.0$ \\
\hline & $60 \min$ & $21.2 \pm 1.7$ & $21.8 \pm 0.0$ \\
\hline & $90 \min$ & $17.9 \pm 1.2$ & $17.9 \pm 0.1$ \\
\hline & $120 \mathrm{~min}$ & $15.6 \pm 1.0$ & $13.8 \pm 0.0$ \\
\hline \multirow{5}{*}{ 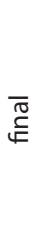 } & fasting & $5.7 \pm 0.3$ & $5.9 \pm 0.0^{*}$ \\
\hline & $30 \mathrm{~min}$ & $21.2 \pm 1.2$ & $17.9 \pm 1.0^{*}$ \\
\hline & $60 \mathrm{~min}$ & $19.3 \pm 0.8$ & $18.0 \pm 0.0^{*}$ \\
\hline & $90 \mathrm{~min}$ & $20.0 \pm 0.8$ & $15.4 \pm 0.0$ \\
\hline & $120 \mathrm{~min}$ & $16.8 \pm 0.6$ & $13.7 \pm 0.1$ \\
\hline
\end{tabular}

Initial glycaemias was evaluated following glucose intraperitoneal load prior to G. robertianum (or distilled water) ingestion and final glycaemia was evaluated 4 weeks later. Data are presented as means \pm SEM for three rats in each group. Values statistically different from glycaemias evaluated before plant extract treatment: ${ }^{*} P<0.05$.

preparations presented a higher respiratory chain activity, since the respiratory rates evaluated in the presence of succinate as a respiratory substrate or in the presence of FCCP, a classic uncoupler, were significantly increased (Table 3). Moreover, mitochondria isolated from GK rats treated with the plant extract showed an improved phosphorylative efficiency, as the respiratory control ratio evaluated in the presence of succinate was significantly higher in those rats than in controls (Table 3). These results indicate both an increased activity of respiratory complexes and a higher coupling between the oxidative and phosphorylative systems.

\section{DISCUSSION}

In the present study, the effects of $G$. robertianum leaf decoctions were evaluated on blood glucose levels. This plant extract is commonly used in popular medicine in Portugal due to its attributed anti-diabetic properties (Castro, 1998; Cunha et al., 2009). However, in vivo studies to support this empirical data are missing.

To evaluate the $G$. robertianum anti-hyperglycaemic potential, studies were performed using a type 2 diabetes animal model widely studied in our laboratory, the Goto-Kakizaki rat (Ferreira et al., 1999a; 1999b; Moreira et al., 2003; Oliveira et al., 2004; Sena et al., 2008). Our results revealed that $G$. robertianum decoction significantly decreased GK rats' occasional glycaemias, as compared with a control group. Nevertheless, evaluation of glycaemia after intraperitoneal glucose administration revealed that the $G$. robertianum decoct induced a significant decrease only $60 \mathrm{~min}$ after glucose load. Similar results were obtained for a Vaccinium myrtillus decoct, another plant extract also used in Portugal due to its supposed anti-diabetic properties (Ferreira et al., 2010). These results, apparently contradictory, probably reflect specific effects in carbohydrate absorption or metabolism induced by these two plant extracts, rather than the stimulation of insulin release and/or glucose uptake by peripheral tissues. Furthermore, these plant extracts also decreased the amount of food ingested, which is in good agreement with the lower occasional glycaemia.

Our previous work with this type diabetes 2 animal model showed that liver mitochondria exhibited enhanced respiratory activity and improved coupling of the phosphorylative and oxidative systems in rats in their first year of life, as compared with non-diabetic Wistar rats of similar ages (Ferreira et al., 1999b; 1999c; 2003), associated with differences in mitochondrial composition (Ferreira et al., 1999a). Also, the liver mitochondria of $\mathrm{GK}$ rats presented an improved antioxidant capacity, compared with Wistar rats (Ferreira et al., 1999a; 2003).

As recent evidence suggests that certain flavonoids as kaempferol, present in G. robertianum leaves (Amaral et al., 2009), can improve mitochondrial biogenesis (Rasbach \& Schnellmann, 2008), the GK rat seemed to us a suitable animal model for evaluation of these plants' extracts effects on OXPHOS by an in vivo assay.

Our results showed that the mitochondrial respiratory activity, assessed in the presence of succinate as a respiratory substrate and ADP (state 4 and state 3 , respectively) or in the presence of the uncoupler FCCP, was significantly augmented in GK rats supplied with G. robertianum decocts. These results point to a higher expression of respiratory complex proteins, which is in good agreement with previous reports indicating an enhancement of mitochondrial biogenesis in the presence of flavonoids (Lagouge et al., 2006; Rasbach \& Schnellmann, 2008; Csiszar et al., 2009).

G. robertianum extract treatment increased the efficiency of coupling between oxidative and phosphorylative systems, since RCR was considerably higher in GK rats consuming this plant extract. Therefore, this higher coupling is probably related with the high content of respiratory complexes and $\mathrm{F}_{0} \mathrm{~F}_{1}$-ATPsynthase and also with mitochondrial membrane lipid adjustments (Ames et al., 1995).

Similar results were obtained for a $V$. myrtillus decoct (Ferreira et al., 2010), probably due to the presence of quercetins in $V$. myrtillus leaves (Rasbach \& Schnellmann, 2008; Riihinen et al., 2008; Davis et al., 2009).

Table 3. Effect of G. robertianum on GK rat liver mitochondrial parameters

\begin{tabular}{|c|c|c|c|c|}
\hline Condition & $\mathrm{nmol} \underset{2}{\mathrm{~V}_{3}} \times \mathrm{mg}_{(\%)}^{-1} \times \mathrm{min}^{-1}$ & $\mathrm{nmol} \underset{2}{\mathrm{~V}_{4} \times \mathrm{mg}^{-1} \times \mathrm{min}^{-1}}$ & $\begin{array}{c}\text { FCCP } \\
\mathrm{nmol} \mathrm{O}_{2} \times \mathrm{mg}^{-1} \times \mathrm{min}^{-1} \\
(\%)\end{array}$ & $\begin{array}{l}\text { RCR } \\
(\%)\end{array}$ \\
\hline Control & $\begin{array}{c}36.4 \pm 4.1 \\
(100.0 \pm 11.2)\end{array}$ & $\begin{array}{c}9.0 \pm 1.0 \\
(100.0 \pm 9.2)\end{array}$ & $\begin{array}{c}42.3 \pm 5.7 \\
(100.0 \pm 13.4)\end{array}$ & $\begin{array}{c}4.2 \pm 0.6 \\
(100.0 \pm 14.0)\end{array}$ \\
\hline G. robertianum & $\begin{array}{c}100.2 \pm 6.3 \\
(275.0 \pm 17.6)^{* * * *}\end{array}$ & $\begin{array}{c}15.5 \pm 1.7 \\
(172.1 \pm 18.4)^{* *}\end{array}$ & $\begin{array}{c}99.1 \pm 5.0 \\
(234.1 \pm 11.7)^{* * * *}\end{array}$ & $\begin{array}{c}6.8 \pm 0.7 \\
(161.9 \pm 15.7)^{* *}\end{array}$ \\
\hline
\end{tabular}

Values of respiratory rates in state 3,4 and FCCP-stimulated respiration (respectively $\mathrm{V}_{3}, \mathrm{~V}_{4}$ and $\mathrm{FCCP}$ ) are expressed as $\mathrm{nmol} \mathrm{O}_{2} \times(\mathrm{mg}$ protein) ${ }^{-1} \times \mathrm{min}^{-1}$ and as percentage of control (GK rats drinking distilled water). Results are presented as mean \pm SEM of triplicates of experiments performed with mitochondrial preparations from three rats in each group. Statistics: ${ }^{* *} P<0.0001 ;{ }^{*} P<0.001$ as compared to controls. 
Indeed, the high content of polyphenolic compounds is also correlated to several medicinal properties attributed to these plants. Anthocyanosides and quercetins found in $V$. myrtillus constitute important therapeutic agents in diabetes, delaying the onset of diabetic complications, generally related to vascular damage induced by oxidative stress (Duke, 1992; Roy et al., 2002; Riihinen et al., 2008), and can be suitable for diabetic patients. Regarding its chemical composition, G. robertianum also has a high content of polyphenols and flavones with a high antioxidant activity, the most significant being 3,4-dimethoxyflavone, homoeriodictyol and kaempferol (Amaral et al., 2009; Neagu et al., 2010).

Due to their essential function in aerobic metabolism, mitochondria are associated with the pathophysiology of diabetes. Indeed, qualitative, quantitative and functional mitochondrial perturbations affecting both the onset of diabetes and associated complications have been identified (Sivitz \& Yorek, 2010). Thus, for all the stated reasons, the valuable effects of $G$. robertianum and $V$. myrtillus leaf decoctions that we named "MitoTeas", particularly their high antioxidant activity and the improvement of mitochondrial OXPHOS, associated with lowering of occasional glycaemia, make these medicinal plants valuable candidates for diabetes therapy. Nevertheless, further studies are required in order to fully explain the mechanisms involved in OXPHOS efficiency improvement by these "MitoTeas".

\section{REFERENCES}

Agius L (2007) New hepatic targets for glycaemic control in diabetes. Clin Endocrinol Metab 21: 587-605.

Amaral S, Mira L, Nogueira JMF, da Silva AP, Florêncio MH (2009) Plant extracts with anti-inflammatory properties - A new approach for characterization of their bioactive compounds and establishment of structure-antioxidant activity relationships. Bioorg Med Chem 17: 1876-1883.

Ames BN, Shigenaga MK, Hagen TM (1995) Mitochondrial decay in aging. Biochim Biophys Acta 1271: 165-170.

Castro V (1998) Chromium in a series of Portuguese plants used in the herbal treatment of diabetes. Biol Trace Elem Res 62: 101-106.

Chance B, Williams GR (1956) The respiratory chain and oxidative phosphorylation. Adv Enzymol 17: 65-134.

Csiszar A, Labinskyy N, Pinto JT, Ballabh P, Zhang H, Losonczy G, Pearson K, de Cabo R, Pacher P, Zhang C, Ungvari Z (2009) Resveratrol induces mitochondrial biogenesis in endothelial cells. Am J Physiol 297: H13-H20.

Cunha AP, Silva AP, Roque AR (2009) Plantas e Produtos Vegetais em Fitoterapia. Fundação Calouste Gulbenkian, Lisboa, Portugal (in Portuguese).

Davis JM, Murphy EA, Carmichael MD, Davis B (2009) Quercetin increases brain and muscle mitochondrial biogenesis and exercise tolerance. Am J Physiol 296: R1071-R1077.

Duke JA (1992) Handbook of phytochemical constitutens of GRAS herbs and other economic plants. CRC Press, Boca Raton.

Engelgau MM, Geiss LS (2000) The burden of diabetes mellitus. In Medical management of diabetes mellitus. Leahy Jl, Clark NG, Cefalu WT, eds, pp 1-17. Mark Dekker, Inc., New York.

Estabrook RE (1967) Mitochondrial respiratory control and the polarographic measurement of ADP:O ratios. Methods Ensymol 10: 41-47.

Ferreira FML, Madeira VMC, Moreno AJ (1997) Interactions of 2,2-bis ( $p$-chlorophenyl)-1,1-dichloroethylene with mitochondrial oxidative phosphorylation. Biochem Pharmacol 53: 299-308.

Ferreira FML, Palmeira CM, Matos MJ, Seiça R, Santos MS (1999a) Decreased susceptibility to lipid peroxidation of Goto-Kakizaki rats: relationship to mitochondrial antioxidant capacity. Life Sci 65: 1013-1025.
Ferreira FML, Palmeira CM, Seiça R, Santos MS (1999b) Alterations of liver mitochondrial bioenergetics in diabetic Goto-Kakizaki rats. Metabolism 48: 1115-1119.

Ferreira FML, Seiça R, Santos MS, Palmeira CM (1999c) Age-related alterations in liver mitochondrial bioenergetics of diabetic GotoKakizaki rats. Acta Diabetol 36: 173-177.

Ferreira FM, Palmeira CM, Seiça R, Moreno AJ, Santos MS (2003) Diabetes and mitochondrial bioenergetics: alterations with age. J Biochem Mol Toxicol 17: 214-222.

Ferreira FM, Peixoto FP, Nunes E, Sena C, Seiça R, Santos MS (2010) Vaccinium myrtillus improves liver mitochondrial oxidative phosphorylation of diabetic Goto-Kakizaki rats. J Med Plants Res 4: 692-696.

Gazotti P, Malmstron K, Crompton M (1979) In Membrane Biochemistry: A laboratory manual on transport and bioenergetics, Carafoli E, Sememza G, eds, pp 62-69. Springer-Verlag, New York.

Gornall AG, Bardawill CJ, David MM (1949) Determination of serum proteins by means of the biuret reaction. J Biol Chem 177: 751-766.

Goto Y, Kakizaki M (1981) The spontaneous-diabetes rat: A model of noninsulin dependent diabetes mellitus. Proc Jpn Acad 57: 381-384.

Jayakumar R V (2010) Herbal medicines for type-2 diabetes. Int J Diab Dev Ctries 30: 111-112.

Lagouge M, Argmann C, Gerhart-Hines Z, Meziane H, Lerin, C, Daussin F, Messadeq N, Milne J, Lambert P, Elliott P, Geny B, Laakso M, Puigserver P, Auwerx J (2006) Resveratrol improves mitochondrial function and protects against metabolic disease by activating SIRT1 and PGC-1alpha. Cell 127: 1109-1122.

Moreira PI, Santos MS, Moreno AJ, Seiça R, Oliveira CR (2003) Increased vulnerability of brain mitochondria in diabetic (Goto-Kakizaki) rats with aging and amyloid- $\beta$ exposure. Diabetes 52: 1449_1456

Neagu E, Roman GP, Radu GL, Nechigor G (2010) Concentration of the bioactive principles in Geranium robertianum extracts through membranare procedures (ultrafiltration). Rom Biotech Lett 15: 50425048.

Oliveira PJ, Seica R, Santos DL, Rolo AP, Sardão VA, Ferreira FML, Palmeira CM, Santos MS, Moreno AJM (2004) Vitamin E or coenzyme Q10 administration is not fully advantageous for heart mitochondrial function in diabetic Goto-Kakizaki rats. Mitochondrion 3: 337-345.

Portha B, Lacraz G, Kergoat M, Homo-Delarche F, Giroix MH, Bailbé D, Gangnerau MN, Dolz M, Tourrel-Cuzin C, Movassat J (2009) The GK rat beta-cell: A prototype for the diseased human beta-cell in type 2 diabetes? Mol Cell Endocrinol 297: 73-85.

Rasbach KA, Schnellmann RG (2008) Isoflavones promote mitochondrial biogenesis. J Pharmacol Exp Ther 325: 536-543.

Reusch JEB (2003) Diabetes, microvascular complications, and cardiovascular complications: what is it about glucose? J Clin Invest 112: 986-988.

Riihinen K, Jaakola L, Kärenlampi S, Hohtola A (2008) Organ-specific distribution of phenolic compounds in bilberry (Vaccinium myrtillus) and 'northblue' blueberry (Vaccinium corymbosum $\mathrm{x} V$. angustifolium). Food Chem 110: 156-160.

Roy S, Khanna, S Alessio, HM Vider J, Bagchi D, Bagchi M, Sen CK (2002) Anti-angiogenic property of edible berries. Free Radic Res 36: 1023-1032.

Ryan EA, Pick ME, Marceaux C (2001) Use of alternative medicines in diabetes mellitus. Diabet Med 18: 242-245.

Sena CM, Nunes E, Gomes A, Santos MS, Proença T, Martins MI, Seiça RM (2008) Supplementation of coenzyme Q10 and $\alpha$-tocopherol lowers glycated hemoglobin level and lipid peroxidation in pancreas of diabetic rats. Nutr Res 28: 113-121.

Sivitz WI, Yorek MA (2010) Mitochondrial dysfunction in diabetes: from molecular mechanisms to functional significance and therapeutic opportunities. Antioxid Redox Signal 12: 537-577.

WHO (World Health Organization) (1980) Expert committee on diabetes mellitus: second report. Tech Rep Ser 646: 1-80.

WHO (World Health Organization) (2006) Definition and diagnosis of diabetes mellitus and intermediate hyperglycaemia: report of a WHO/IDF consultation.

Yorek MA (2003) The role of oxidative stress in diabetic vascular and neural disease. Free Radic Res 37: 471-480.

Yu PC, Bosnyak Z, Ceriello A (2010) The importance of glycated haemoglobin (HbA1c) and postprandial glucose (PPG) control on cardiovascular outcomes in patients with type 2 diabetes. Diabetes Res Clin Pract 89: 1-9. 